\title{
Energy Saving Mechanism of the Dual Controls
}

\author{
Hui SONG ${ }^{1,2, a,{ }^{*}, \text { Bo HUANG }}{ }^{2, b}$
}

\author{
${ }^{1}$ School of Economy and Management, Yancheng Institute of Technology, Yancheng 224051, China \\ ${ }^{2}$ Department of Geography and Resource Management, the Chinese University of Hong Kong, \\ Hong Kong 999077, China \\ asonghui272@163.com, bbohuang@cuhk.edu.hk \\ *Corresponding author: songhui272@163.com
}

\begin{abstract}
Keywords: Dual controls, Forcing mechanism, Energy conservation measures, Exponential decomposition.
\end{abstract}

\begin{abstract}
The measure matching with target constraint of regional energy intensive (EI) control or overall energy consumption control (dual controls) generally owns dual energy saving effects through process technology innovation and economy structure adjustment. And the dual controls are the important countermeasures to strength national priority strategy of saving energy in recent years, whose role is to reasonably match regional agents' technical energy saving (TES) and structural energy saving (SES) in order to achieve energy saving effectively in China. With the approach of LMDI, we found that: (1) Changes in China's energy consumption structure have only promoted the substitute between different types of primary energy and have not had a significant impact on total energy consumption from 2006. (2) The single target constraint of EI is not conducive to the dual efficacy of TES and SES. Energy saving coefficient indicates that dual controls are conductive to improve energy-saving efficiency. (3) And the energy saving effect of process technology innovation went down in the period of 2015-2016 compared to the period of 2014-2015.
\end{abstract}

\section{Introduction}

The average annual growth rate of energy consumption in China was 5.10\% from 2005 to 2015. At this rate, China's total energy consumption would reach 5.514 billion tons coal equivalent (tce) in 2020, which would exceed the goal of 5 billion tce set in the 13th Five-Year Plan(FYP) for Energy Development, and would be far more than the target of 4.8 billion tce set in the Energy Development Strategic Action Plan (2014-2020). From 2010 to 2015, the average annual growth rate of energy consumption in China slowed down to $3.58 \%$. At this rate, China's total energy consumption would reach 5.125 billion tce in 2020, which also would exceed the total energy consumption target of the 13th FYP for Energy Development.

To control total energy consumption in China by 2020 under the target of 5 billion tce, the average annual energy growth rate from 2015 to 2020 must be controlled within the range of $3.07 \%$. And to control the amount of energy consumption in China by 2030 under the 6 billion tce according to the Strategy of Energy Production and Consumption Revolution (2016-2030), the average annual energy consumption growth rate from 2015 to 2020 must be controlled within the range of $2.25 \%$ based on 2015 energy consumption of 4.299 billion tce. If the energy consumption in China is 5 billion tce in 2020 , the growth rate of energy consumption should be controlled within the range of $1.84 \%$ from 2020 to 2030 in order to match the upper limit target of energy consumption in 2030.

The 19th National Congress report pointed out that China's economy has shifted from the stage of high-speed growth to the stage of high-quality development. It can be seen that energy saving still is a major issue at this stage of China's economy development.

In order to promote the transformation from an energy-based and extensive economy to an intensive economy, energy intensity (EI) as a quantitative target constraint indicator was firstly implemented as a Chinese economic policy to strengthen energy saving strategy in 2006 (Li and Liu, 2014)[1]. And the requirement of ceiling on overall energy consumption (OEC) was presented in the 
12th FYP for Comprehensive Energy Conservation and Emission Reduction Work as a soft target constraint for energy saving in 2011.

Afterwards, the target constraints of regional EI and OEC controls were clearly put forward to strengthen the national priority strategy of energy saving in the 12th FYP for Energy Development in 2013, which remarked that the dual control system in the fields of energy conservation was initially founded in China.

So what kind of the energy saving mechanism does result from the dual control system? What kind of energy saving effect result from the mechanism? And how to identify whether there is rational match between the dual controls with the energy saving effects? All of those above are the aims of this article to explore.

\section{Energy Saving Mechanism of Dual Controls}

\section{Energy Consumption Control Measures Resulting from the Dual Controls}

Ceiling on regional EI and OEC should satisfy the fair development of regional economy and society (Li and Liu, 2014; Li, et al, 2016; Ruan and Ning, 2013)[1,2,3]. Of course, the target constraint of regional EI may generally force the technology progress in the fields of regional industry (Wang and Qi, 2014; Lin and Du, 2014; Zhou, 2016; Sun, et al, 2013)[4,5,6,7], increase production efficiency (Lin and Du, 2014)[5], close backward production capacity (Jonathan, et al, 1998)[8], and may also stimulate the market to form reasonable energy prices (Li, et al, 2016; Zhou, 2016)[2,6].

And it is a new topic to control the overall energy consumption (Zhang, 2011), and the target constraint of regional OEC may generally force regional industry restructuring, export restructuring, economic development and energy consumption restructuring, residents' lifestyle adjusting (Jonathan, et al, 1998; Dai, 2015)[8,9], and the rational planning of regional GDP output goals (Ruan and Ning, 2013)[3] etc.

Therefore, the enforcement of regional EI and OEC control policies is conducive to force regional energy saving measures to be adopted and implemented effectively.

\section{Energy Saving Mechanism of Energy Consumption Control Measures}

One measure forced by dual controls may contribute energy saving by two ways. For example, reasonable energy price is one of the energy consumption control measures to increase energy consumption efficiency ( $\mathrm{Li}$ and $\mathrm{Liu}, 2014$; $\mathrm{Li}$, et al, 2016)[1,2]. Differential power prices are faced to the enterprises in high energy-consuming steel industries according to their devices, which have been classified to encouraged, restricted and eliminated categories according to their electricity efficiency by the National Development and Reform Commission to eliminate the backward production capacity of high-energy-consuming industries. The implementation of this measure may promote the enterprises who own restricted and eliminated devices to realize technical energy saving (TES) through technical innovation in production process, and/or to realize structural energy saving (SES) through structural optimization such as updating equipment structure and adjusting output structure while ensuring the economic output relatively stable. Obviously, the measure forced by dual controls may lead to TES when the regional economy agent such as enterprise or government agency emphasizes on energy saving through technical innovation to ceil on the regional EI, and lead to SES when the regional economy agent emphasizes on energy saving through economy restructuring to ensure the regional economic total quantity.

Why was the policy of OEC control enhanced while the policy of EI control was being implemented in China? The dual controls would be able to ensure synergy between TES and SES. For example, the implementation of quantified EI control in 2006 brought China's EI down from 1.357tce per ten thousand yuan in 2006 to 0.874 tce per ten thousand yuan in 2016, whose base period is the year 2005. And during which, the OEC increased rapidly from 2.214 billion tce in 2005 to 4.36 billion tce in 2016 with the growth of China's GDP. Obviously, the effect of TES (ETES), that the negative increment in total energy consumption compared with the previous period resulting from technical progress, is not beyond the effect of SES (ESES), that the positive increment in total energy 
consumption compared with the previous period resulting from economy growth. So target constraint of OEC was implemented to limit regional energy consumption through means of regional self-economy regulation.

The energy-saving mechanism of dual controls is shown in Fig.1. The dual controls guide regional economy agents in choosing measures and making them reasonable match each other to achieve technical and structural energy saving effectively by the way of promoting the technology levels of energy efficiency and adjusting the economy structure to satisfy the target of established economy output. And then, energy saving effects which include ETES and ESES will react on rationally adjusting regional targets of dual controls in the national view. Of course, the national energy saving effects may be explored with the mechanism of dual controls.

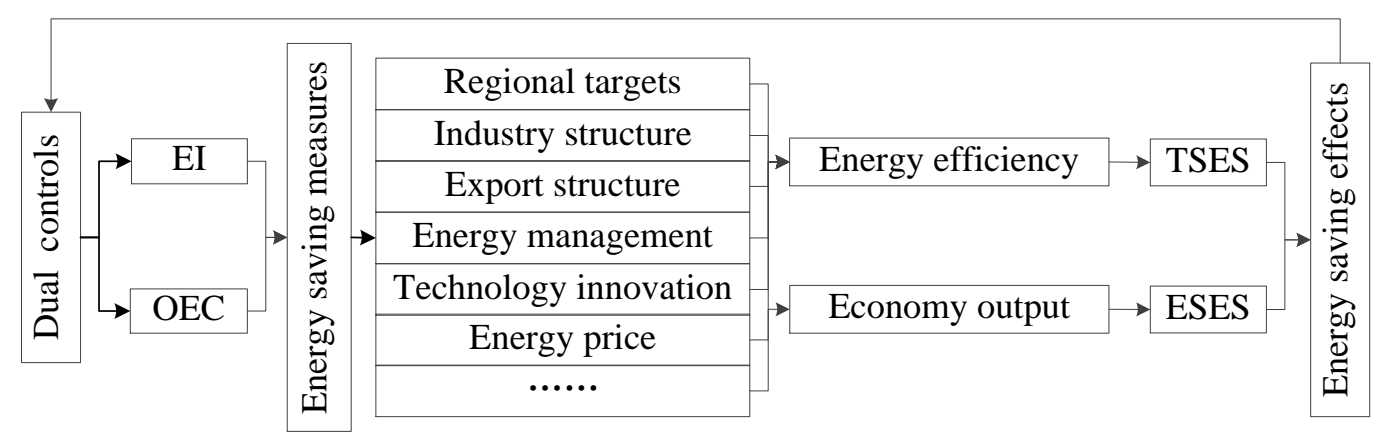

Fig.1 Energy saving mechanism of dual controls

\section{Methodology and Data}

Index decomposition approach can be decomposed based on the Laplace index factor, or it can be decomposed based on the Divisia index factor. Because of the advantages of full-division, no-residual, and easy-to-use etc. compared to other methods (Ang, Zhang, 2000; Ang, Liu, 2004)[10,11], the logarithmic mean Divisia index (LMDI) is a commonly used method for studying related issues in the energy fields (Zhao, Li, 2011; Robin, Mark, 2013)[12,13]. Therefore, the addition form of the LMDI (Ang, Liu, 2004)[11] is adopted to study the energy saving effects of dual controls in China. And the incremental model of national energy consumption is constructed as Eq. (1).

$$
E_{t}=\sum_{i} E_{i, t}=\sum_{i} \frac{E_{i, t}}{E_{t}} \cdot \frac{E_{t}}{G_{t}} \cdot G_{t}=\sum_{i} s_{i, t} \cdot d_{t} \cdot G_{t}
$$

Where $E_{t}$ is total energy consumption of China in year $t ; E_{i t}$ is the consumption of energy $i$ in year $t$ and which $i$ represents four kinds of primary energy such as coal, petroleum, natural gas, non-fossil energy. $G_{t}$ is national gross domestic product (GDP) in year $t$. Obviously, $s_{i t}$ and $d_{t}$ represent national energy consumption structure and energy efficiency respectively. The increment of total energy consumption from year $t-1$ to year $t$ can be expressed as Eq. (2).

$$
\Delta E_{t}=E_{t}-E_{t-1}=\Delta E_{s}+\Delta E_{d}+\Delta E_{G}
$$

Where $E_{t-1}$ represent the total energy consumption in year $t-1 . \Delta E_{s}, \Delta E_{d}$ and $\Delta E_{G}$ represent respectively the effect of energy consumption structure (EECS) which the increment of total energy consumption results from the change of energy consumption structure, ETES and ESES. And the contributions of each component to the increment of total energy consumption can be calculated with the Eq. (3), Eq. (4) and Eq. (5). 


$$
\begin{aligned}
& \Delta E_{s}=\sum_{i} \frac{E_{i, t}-E_{i, t-1}}{\ln E_{i, t}-\ln E_{i, t-1}} \ln \left(\frac{s_{i, t}}{s_{i, t-1}}\right) \\
& \Delta E_{d}=\sum_{i} \frac{E_{i, t}-E_{i, t-1}}{\ln E_{i, t}-\ln E_{i, t-1}} \ln \left(\frac{d_{t}}{d_{t-1}}\right) \\
& \Delta E_{G t}=\sum_{i} \frac{E_{i, t}-E_{i, t-1}}{\ln E_{i, t}-\ln E_{i, t-1}} \ln \left(\frac{G_{t}}{G_{t-1}}\right)
\end{aligned}
$$

The research data from 2006 to 2016 used in this article include total primary energy consumption whose unit is $10^{4}$ tce, its structure, and GDP whose unit is $10^{8}$ yuan in China. The value of GDP is calculated again according to the comparable price in 2005 in order to achieve equivalent comparison between different years. And the data come from China Statistical Yearbook from 2010 to 2017.

\section{Results and Discussions}

Table 1 shows EECS, ETES and ESES that resulting from changes of energy consumption structure,

\begin{tabular}{|c|c|c|c|c|c|c|c|c|}
\hline \multirow[b]{2}{*}{ periods } & \multicolumn{5}{|c|}{ EECS (10 tce) } & \multirow[b]{2}{*}{$\begin{array}{l}\text { ETES } \\
\left(10^{4} \text { tce }\right)\end{array}$} & \multirow{2}{*}{$\begin{array}{l}\text { ESES } \\
\left(10^{4} \text { tce }\right)\end{array}$} & \multirow{2}{*}{$\begin{array}{l}\text { energy } \\
\text { saving } \\
\text { coefficient }\end{array}$} \\
\hline & coal & petroleum & $\begin{array}{l}\text { nature } \\
\text { gas }\end{array}$ & $\begin{array}{l}\text { non-fossil } \\
\text { energy }\end{array}$ & sum & & & \\
\hline 2006-2007 & 298.8 & -1493.6 & 897.0 & 298.8 & 1.0 & -14778.9 & 39752.9 & 0.372 \\
\hline 2007-2008 & -3159.9 & -948.0 & 1264.4 & 2844.8 & 1.3 & -19951.9 & 29119.6 & 0.685 \\
\hline 2008-2009 & 328.3 & -984.9 & 328.3 & 328.3 & 0.1 & \begin{tabular}{|l|}
-13979.7 \\
\end{tabular} & 29494.6 & 0.474 \\
\hline $2009-2010$ & -8356.2 & 3483.6 & 1742.6 & 3136.0 & 6.1 & -10674.6 & 35190.5 & 0.303 \\
\hline 2010-2011 & 3737.2 & -2241.7 & 2244.0 & -3734.4 & 5.1 & -7641.9 & 34031.8 & 0.225 \\
\hline 2011-2012 & \begin{tabular}{|l|}
-6706.7 \\
\end{tabular} & 789.1 & 789.2 & 5131.4 & 3.0 & -14741.0 & 29833.0 & 0.494 \\
\hline $2012-2013$ & -4504.1 & 409.5 & 2048.0 & 2047.7 & 1.1 & -15817.9 & 30591.8 & 0.517 \\
\hline 2013-2014 & -7583.8 & 1264.1 & 1685.6 & 4635.6 & 1.5 & -20781.7 & 29673.2 & 0.700 \\
\hline 2014-2015 & -8129.0 & 3850.8 & 855.7 & 3423.0 & 0.6 & -24502.9 & 28601.3 & 0.857 \\
\hline $2015-2016$ & -7359.8 & 0.0 & 2164.9 & 5195.9 & 1.0 & -21877.9 & 27971.8 & 0.782 \\
\hline
\end{tabular}
technical innovation and economic structure. And the two later factors are forced by dual controls.

Table 1. Energy saving effects of dual controls

\section{EECS}

We found that there is inevitably substitute law in four kinds of primary energy due to the change of energy consumption structure shown in table 1. From 2006 to 2011, the substitute law characterizes increasing consumption of nature gas and non-fossil energy with decreasing consumption of coal and petroleum. From 2011 to 2016, the substitute law characterizes increasing consumption of petroleum, nature gas and non-fossil energy with decreasing consumption of coal only. Although the increment of every kind of primary energy consumption is relative large, EECS summing of four increments is relative low.

During the period from 2006 to 2016, the largest sum increment of total energy consumption due to the change of energy consumption structure is $6.110^{4}$ tce from 2009 to 2010 , and the least sum increment of total energy consumption due to the change of energy consumption structure is 0.1 $10^{4}$ tce from 2008 to 2009. Obviously, EECS has a negligible impact on China's total energy consumption compared with ETES or ESES.

Based on the above analysis, we can deduce that the adjustment of national energy consumption structure is mainly to promote substitute between four kinds of primary energies and to have a negligible impact on the total energy consumption. And from the fact of energy consumption 
structure having no evident impact on the nationally total energy consumption, we believe that there will still be a rigid demand of energy consumption in the near future in China.

\section{ETES and ESES}

The result was checked that the difference between the ratio of ETES to ESES and the point (end point) elasticity of energy consumption tending to a constant of -1 . Owing to this, we call the absolute ratio energy saving coefficient which is shown in table 1. Energy saving coefficient describes relative energy saving efficiency between ETES and ESES. The larger energy saving coefficient means dual controls more efficient in energy saving.

Target constraint of regional EI only was implemented from 2006 to 2010 in order to saving energy consumption through improving technology level. In this period, ETES and ESES fluctuated and energy saving coefficient also fluctuated in low position, which shew that national energy saving system did not work effectively.

With target constraint of regional OEC was implemented from 2011, dual-control system came into being in the period from 2011 to 2016. ETES increasing from -7641.9 $10^{4}$ tce to $-21877.910^{4}$ tce and ESES decreasing from $34031.810^{4}$ tce to $27971.810^{4}$ tce in this period ensured the energy saving coefficient going up from 0.225 to 0.782 , which shew that national energy saving system did work effectively.

Of course, compared with the period of 2014-2015, ETES declined more evidently in the period of 2015-2016, which resulted in energy saving coefficient declined. This meant that energy saving ability with process technology innovation in the period of 2015-2016 was deficient in stability.

\section{Conclusion}

The measure matching with target constraint of regional EI or OEC generally owns dual energy saving effects through process technology innovation and economy structure adjustment. That is to say, the target constraint of EI will help regional agents strengthen energy saving through technology innovation, and the target constraint of OEC will help regional agents strengthen energy saving through economy structure adjustment in the course of national economy development. The role of the dual controls is to reasonably match TES and SES and achieve effective energy saving. And the final effect of dual controls depends on regional agents' choice according to energy saving efficiency between TES and SES.

Based on the approach of LMDI, we found that in the period of 2006-2016, changes in China's energy consumption structure have only promoted the substitute between different types of primary energy and have not had a significant impact on total energy consumption. The single target constraint of EI is not conducive to the dual efficacy of TES and SES. Energy saving coefficient indicates that dual controls are conductive to improve national energy-saving efficiency.

In order to effectively exert dual controls' function to promote energy saving in China, the following suggestions are put forward.

Firstly, one hierarchical management system should be formed and run with target constraints of dual controls between the central and the regional. Targets of the dual controls should be updated timely by the central with the actual situation of regional economy and society development. And the regional agents should pay attention to reasonably match energy saving measures with their potential ability in technological innovation and economy structure adjustment.

Secondly, the transformation of energy consumption structure should be strengthened in China. The rigidity of energy consumption demand provides the possibility of introducing the transformation of energy consumption structure in China owing to the changes of energy consumption structure having hardly any influence in the increment of total energy consumption. On the basis of the dual control constraints, target constraint of regional energy consumption structure should be introduced, which may be implemented as soft constraint at beginning, to promote green energy consumption and structure optimization. 


\section{Acknowledgement}

This research was financially supported by the National Philosophy and Social Science Foundation, China (No.14BJY215).

\section{References}

[1]F Y Li, W D Liu. The Effect of the Energy Intensity Index of the Twelfth Five-Year Plan on China's Regional Economic Development. China Soft Science, 2 (2014).

[2]H M Li, X F Zhao. China's numerical management system for reducing national energy intensity. Energy Policy 94, 7 (2016).

[3]B X Ruan, Z J Ning. Energy Efficiency Decomposition, "Double Control" Objectives and Zhejiang Province's "Twelfth Five Year Plan" Energy Conservation and Consumption Reduction Models, Approaches and Measures. Science Bulletin, 7 (2013).

[4]B B Wang, S Z Qi. Biased technological progress, factor substitution, and China's industrial energy intensity. Economic Research, 2 (2014).

[5]B Q Lin, K R Du. Understanding the change of China's energy intensity: An integrated decomposition framework. World Economy, 4 (2014).

[6]W Zhou. Heterogeneous impact of energy prices, efficiency improvement, and technological progress on energy intensity in the industrial sectors. Journal of Quantitative \& Technical Economics, 2 (2016).

[7]Q G Sun, J X Guo, Shi B. Spatial Spillover Effects of Energy Intensity among Provinces in China. China Population, Resource and Environment, 11 (2013).

[8]E S Jonathan, D L Mark. Energy efficiency in china: accomplishments and challenges. Energy Policy 26, 11 (1998).

[9]Y D Dai, B Lu, C Feng. Total Energy Consumption Control and Energy Saving in China during the 13th Five-Year Plan Period. Journal of Beijing Institute of Technology (Social Sciences), 1 (2015).

[10]B W Ang, F Q Zhang. A survey of index decomposition analysis in energy and environmental studies. Energy 25, 12 (2000).

[11]B W Ang, F L Liu. Decomposition analysis for policymaking in energy: Which is the preferred method?. Energy Policy 32, 4 (2004).

[12]X L Zhao, N Li. Analysis on the Change of Energy Consumption Structure of Chinese Residents. China Soft Science, 11 (2011).

[13]C Robin, S Mark. The energy-GDP nexus; addressing an old question with new methods. Energy Economics 36, 3 (2013). 